\title{
Verticillin G, a New Antibacterial Compound from Bionectra byssicola
}

\author{
Chang-Ji Zheng, Soo-Hee Park, Hiroyuki Koshino, Young-Ho Kim, Won-Gon Kim
}

Received: July 31, 2006 / Accepted: December 1, 2006

(C) Japan Antibiotics Research Association

\begin{abstract}
A new epidithiodioxopiperazine compound named verticillin $G$ along with the known compound verticillin $\mathrm{D}$ has been isolated from the mycelium of liquid fermentation cultures of a fungal strain Bionectra byssicola F120. The structure of verticillin $G$ was determined on the basis of MS and NMR data. Verticillin G inhibited the growth of Staphylococcus aureus including methicillinresistant and quinolone-resistant $S$. aureus with MIC $(\mu \mathrm{g} / \mathrm{ml})$ of $3 \sim 10$.
\end{abstract}

Keywords verticillin G, epidithiodioxopiperazine, antiMRSA, Bionectra byssicola

Gram-positive eubacteria are representative of pathogenic microorganisms. Especially, Staphylococcus aureus is the most clinically important of these pathogens because of its exceptional virulence, stress tolerance, and capacity to accumulate antimicrobial resistances [1]. Methicillinresistant $S$. aureus (MRSA) is known as a major nosocomial pathogen which has also developed resistance to many other antibiotics. Moreover, MRSA has been reported to acquire resistance to the last-resort antibiotic, vancomycin [2]. These facts suggest that $S$. aureus would fully acquire resistance to vancomycin in the near future. Therefore, it is increasingly important and necessary to find new classes of antimicrobials.

In the course of our screening for new antibacterials from microbial resources, a new epidithiodioxopiperazine compound named verticillin G (1) together with the known compound verticillin D (2) was isolated from the mycelium of liquid fermentation cultures of a fungal strain Bionectra byssicola F120 (Fig. 1). Compound $\mathbf{1}$ is a new derivative of dimeric epidithiodioxopiperazine compounds such as verticillins $\mathrm{A} \sim \mathrm{F}[3,4]$, leptosins $\mathrm{A} \sim \mathrm{C}, \mathrm{K}, \mathrm{K}_{1}$ and $\mathrm{K}_{2}[5$, 6], Sch52900 [7], chaetosin and chetracin A [8].

In this paper, we report the fermentation, isolation, structure determination and anti-MRSA activity of $\mathbf{1}$.

\section{Fermentation and Isolation}

Fermentation was carried out in a liquid culture medium containing YPS medium (glucose $2 \%$, yeast extract $0.2 \%$, peptone $0.5 \%, \mathrm{MgSO}_{4} \cdot 7 \mathrm{H}_{2} \mathrm{O} 0.05 \%$, and $\mathrm{KH}_{2} \mathrm{PO}_{4} 0.1 \%$, $\mathrm{pH} 5.7$ before sterilization). A piece of the strain $\mathrm{F} 120$ from a mature plate culture was inoculated into a $500-\mathrm{ml}$ Erlenmeyer flask containing $80 \mathrm{ml}$ of the above sterile seed liquid medium and cultured on a rotary shaker $(150 \mathrm{rpm})$ at $28^{\circ} \mathrm{C}$ for 3 days. For the production of active compounds, $15 \mathrm{ml}$ of the seed culture was transferred into a $1000-\mathrm{ml}$ Erlenmeyer flask containing $300 \mathrm{ml}$ of the YPS medium, and cultivated on a rotary shaker $(150 \mathrm{rpm})$ for 7 days at $28^{\circ} \mathrm{C}$. After incubation, the fermented liquid cultures $(73$ liters) were centrifuged at $6000 \mathrm{rpm}$ for 20 minutes, then only the mycelium parts were extracted with $80 \%$ acetone. The acetone extracts was concentrated in vacuo to an aqueous solution, which was then extracted with an equal volume of EtOAc three times. The EtOAc extract $(5 \mathrm{~g})$ was subjected to Silica gel (Merck Art No. 7734.9025) column chromatography followed by stepwise elution of $\mathrm{CHCl}_{3}$ -
W.-G. Kim (Corresponding author), C.-J. Zheng, S.-H. Park: Korea Research Institute of Bioscience and Biotechnology, P.O. Box 115, Yusong, Daejeon 305-600, Republic of Korea, E-mail: wgkim@kribb.re.kr
Y.-H. Kim: Chungnam National University, College of Pharmacy, Daejeon 305-764, Republic of Korea

H. Koshino: Molecular Characterization Team, RIKEN, Hirosawa 2-1, Wako, Saitama 351-0198, Japan 


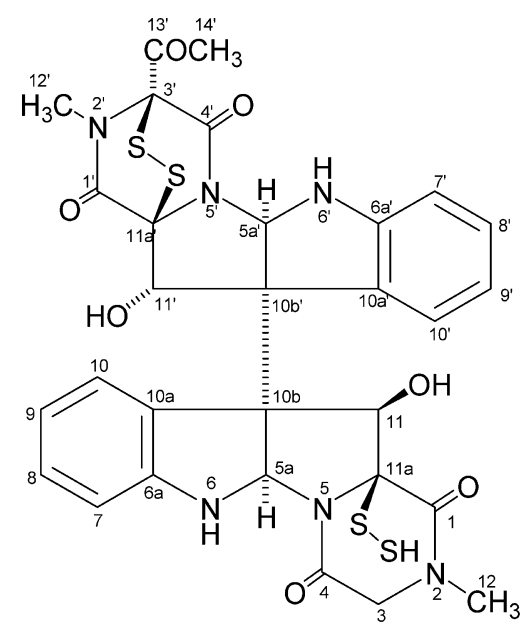

1

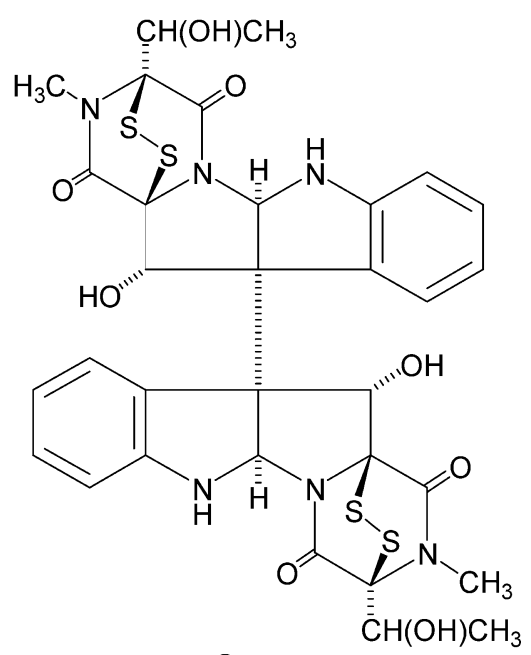

2

Fig. 1 Structures of $\mathbf{1}$ and $\mathbf{2}$.

Table 1 Physico-chemical properties of 1

\begin{tabular}{ll}
\hline Appearance & White powder \\
{$[\alpha]_{D}^{25}$} & $+467.6(c 0.2, \mathrm{MeOH})$ \\
ESI-MS $(\mathrm{m} / \mathrm{z})$ & $713(\mathrm{M}+\mathrm{H})^{+}$ \\
HRESI-MS $(\mathrm{m} / \mathrm{z})$ & \\
$\quad$ found. & $713.09558(\mathrm{M}+\mathrm{H})^{+}$ \\
$\quad$ calcd. & 713.09751 \\
Molecular formula & $\mathrm{C}_{30} \mathrm{H}_{28} \mathrm{~N}_{6} \mathrm{O}_{7} \mathrm{~S}_{4}$ \\
UV $\lambda_{\max } \mathrm{nm}(\log \varepsilon)(\mathrm{MeOH})$ & $215(4.79), 301(3.79)$ \\
IR $v_{\max }^{\mathrm{KBr}} \mathrm{cm}^{-1}$ & $3402,2921,1673,1422,1224$ \\
\hline
\end{tabular}

$\mathrm{MeOH}(100: 1,50: 1)$. The active fractions eluted with $\mathrm{CHCl}_{3}-\mathrm{MeOH}(50: 1)$ were pooled and concentrated in vacuo. The residue dissolved in $\mathrm{MeOH}$ was further purified by reversed-phase HPLC column (YMC $\mathrm{C}_{18}, 10 \times 250 \mathrm{~mm}$ ) chromatography. The column was eluted with $\mathrm{MeOH}-\mathrm{H}_{2} \mathrm{O}$ $(75: 25)$ at a flow rate of $5 \mathrm{ml} /$ minute to afford $1(2.9 \mathrm{mg})$ and $2(35 \mathrm{mg})$ at retention times of 20.5 and 24.3 minutes, respectively.

\section{Structure Elucidation}

Physicochemical properties of $\mathbf{1}$ are shown in Table 1 . The molecular formula of 1 was determined to be $\mathrm{C}_{30} \mathrm{H}_{28} \mathrm{~N}_{6} \mathrm{O}_{7} \mathrm{~S}_{4}$ on the basis of high resolution ESI-MS $\left[(\mathrm{M}+\mathrm{H})^{+}\right.$, $713.09558 \mathrm{~m} / \mathrm{z}\left(-1.93 \mathrm{mmu}\right.$ error)] in combination with ${ }^{1} \mathrm{H}$ and ${ }^{13} \mathrm{C}$ NMR data. The IR data suggested the presence of a carboxyl $\left(1673 \mathrm{~cm}^{-1}\right)$, and a hydroxyl $\left(3402 \mathrm{~cm}^{-1}\right)$ moiety. The ${ }^{1} \mathrm{H}$ and ${ }^{13} \mathrm{C}$ NMR data (Table 2) together with ${ }^{1} \mathrm{H}-{ }^{1} \mathrm{H}$ COSY, DEPT and HMQC data suggested the presence of two 1,2-disubstituted benzenes, two isolated methines ( $\delta$
$6.46, \mathrm{~s}, \delta 76.4$ and $\delta 7.49, \mathrm{~s}, \delta 79.0)$ attached to two nitrogens, two isolated hydroxy methines ( $\delta 4.35$, s, $\delta 75.0$ and $\delta 4.85, \mathrm{~s}, \delta 84.2$ ), an isolated methylene, an isolated methyl, two $N$-methyl groups, a ketone carbonyl, four amide carbonyls ( $\delta 166.4,165.8,163.9$, and 163.2), and five quaternary $s p^{3}$ carbons $(\delta 87.2,85.7,78.6,58.3$, and 56.2). These spectral data of 1 were similar to those of compound 2, which was identified as verticillin $\mathrm{D}$ by comparison with the literature [3] and on the basis of various spectroscopic analyses. However, these spectral data of $\mathbf{1}$ showed a double set of signals, suggesting that $\mathbf{1}$ was not dimeric. The major differences between $\mathbf{1}$ and $\mathbf{2}$ in ${ }^{1} \mathrm{H}$ and ${ }^{13} \mathrm{C}$ NMR data is that the isolated methyl $(\delta 2.30, \mathrm{~s}$, $\delta$ 25.1), the ketone carbonyl ( $\delta$ 196.3), and the isolated methylene ( $\delta 3.70, \mathrm{~d}, J=17.6 \mathrm{~Hz}$ and $\delta 4.50, \mathrm{~d}, J=17.6 \mathrm{~Hz}$, $\delta 52.6)$ were newly observed in 1 instead of the signals of $-\mathrm{CH}(\mathrm{OH}) \mathrm{CH}_{3}$ in 2. Placements of the methyl, the ketone carbonyl, and the methylene were determined by HMBC spectral data (Fig. 2). The methyl protons at $\delta 2.30$ (14' $\mathrm{H}_{3}$ ) were long range coupled to the ketone carbonyl carbon at $\delta 196.3\left(\mathrm{C}-13^{\prime}\right)$ and the quaternary $s p^{3}$ carbon at $\delta 87.2$ $\left(\mathrm{C}-3^{\prime}\right) . N$-Methyl proton at $\delta 2.80\left(12^{\prime}-\mathrm{H}_{3}\right)$ were coupled to the carbon of $\mathrm{C}-3^{\prime}$ and the amide carbonyl carbon at $\delta 166.4\left(\mathrm{C}-1^{\prime}\right)$. This spectral data revealed the presence of the acetyl group which was attached to $\mathrm{C}-3^{\prime}$ of one epidithiodioxopiperazine ring. On the other hand, the methylene protons at $\delta 3.70\left(3-\mathrm{H}_{\mathrm{a}}\right)$ and $4.50\left(3-\mathrm{H}_{\mathrm{b}}\right)$ were long range coupled to the other $N$-methyl carbon at $\delta 33.8$ (C-12) and two amide carbonyl carbons at $\delta 165.8$ (C-4) and 163.2 (C-1). Also, long range couplings were also observed from the $\mathrm{N}$-methyl protons of $12-\mathrm{H}_{3}$ to the amide carbonyl carbon of $\mathrm{C}-1$ and the methylene carbon of $\mathrm{C}-3$. 
Table $2{ }^{1} \mathrm{H}$ and ${ }^{13} \mathrm{C}$ NMR spectral data for $\mathbf{1}$

\begin{tabular}{|c|c|c|c|}
\hline Position & $\delta_{\mathrm{H}}$ (mult., $J \mathrm{~Hz}$ ) & $\delta_{\mathrm{C}}$ & \\
\hline 1 & & 163.2 & C \\
\hline \multirow[t]{2}{*}{3} & На 3.70 (d, 17.6) & 52.6 & $\mathrm{CH}_{2}$ \\
\hline & $\mathrm{Hb} 4.50(\mathrm{~d}, 17.6)$ & & \\
\hline 4 & & 165.8 & C \\
\hline $5 a$ & 6.46 (s) & 76.4 & $\mathrm{CH}$ \\
\hline $6 a$ & & 148.6 & C \\
\hline 7 & $6.48(\mathrm{dd}, 7.4,1.0)$ & 110.0 & $\mathrm{CH}$ \\
\hline 8 & $6.95(\mathrm{td}, 7.4,1.0)$ & 129.4 & $\mathrm{CH}$ \\
\hline 9 & $6.62(\mathrm{td}, 7.4,1.0)$ & 120.2 & $\mathrm{CH}$ \\
\hline 10 & $7.36(\mathrm{dd}, 7.4,1.0)$ & 123.2 & $\mathrm{CH}$ \\
\hline $10 a$ & & 125.0 & $\mathrm{C}$ \\
\hline $10 b$ & & 58.3 & C \\
\hline 11 & 4.35 (s) & 75.0 & $\mathrm{CH}$ \\
\hline $11 a$ & & 85.7 & $\mathrm{C}$ \\
\hline 12 & 2.95 (s) & 33.8 & $\mathrm{CH}_{3}$ \\
\hline $1^{\prime}$ & & 166.4 & C \\
\hline $3^{\prime}$ & & 87.2 & $\mathrm{C}$ \\
\hline $4^{\prime}$ & & 163.9 & C \\
\hline $5^{\prime} \mathrm{a}$ & 7.49 (s) & 79.0 & $\mathrm{CH}$ \\
\hline $6^{\prime} a$ & & 150.4 & $\mathrm{C}$ \\
\hline $7^{\prime}$ & $6.34(\mathrm{dd}, 7.8,1.0)$ & 109.0 & $\mathrm{CH}$ \\
\hline $8^{\prime}$ & $6.89(\mathrm{td}, 7.8,1.0)$ & 130.4 & $\mathrm{CH}$ \\
\hline $9^{\prime}$ & $6.49(\mathrm{td}, 7.8,1.0)$ & 119.1 & $\mathrm{CH}$ \\
\hline $10^{\prime}$ & $7.06(\mathrm{dd}, 7.8,1.0)$ & 125.8 & $\mathrm{CH}$ \\
\hline $10^{\prime} \mathrm{a}$ & & 126.8 & $\mathrm{C}$ \\
\hline $10^{\prime} b$ & & 56.2 & C \\
\hline $11^{\prime}$ & 4.85 (s) & 84.2 & $\mathrm{CH}$ \\
\hline $11^{\prime} a$ & & 78.6 & $\mathrm{C}$ \\
\hline $12^{\prime}$ & 2.80 (s) & 30.6 & $\mathrm{CH}_{3}$ \\
\hline $13^{\prime}$ & & 196.3 & C \\
\hline $14^{\prime}$ & 2.30 (s) & 25.1 & $\mathrm{CH}_{3}$ \\
\hline
\end{tabular}

${ }^{1} \mathrm{H}$ and ${ }^{13} \mathrm{C}$ NMR spectral data were measured at 600 and $125 \mathrm{MHz}$, respectively, in $\mathrm{CDCl}_{3}+\mathrm{CD}_{3} \mathrm{OD}$. The assignments were aided by ${ }^{1} \mathrm{H}-{ }^{1} \mathrm{H}$ COSY, DEPT, HMQC, and HMBC.

These spectral data clearly indicated the presence of the methylene at $\mathrm{C}-3$ in the other epidithiodioxopiperazine ring. Together with the molecular formula, the ${ }^{13} \mathrm{C}$ chemical shift $(\delta 85.7)$ of the quaternary $s p^{3}$ carbon of C-11a indicated that the hydrodisulfide group should be attached to $\mathrm{C}-11 \mathrm{a}$ in the dioxopiperazine ring. The remaining structure was also confirmed by HMBC spectral data (Fig. 2 ). The relative configuration of $\mathbf{1}$ was examined by NOESY spectral data (Fig. 3). Strong NOEs among $11^{\prime}-\mathrm{H}$, $10^{\prime}-\mathrm{H}$ and $5 \mathrm{a}-\mathrm{H}$ were observed, while no NOE between $11^{\prime}-\mathrm{H}$ and $5^{\prime} \mathrm{a}-\mathrm{H}$ was observed. These data indicated that $11^{\prime}-\mathrm{H}$ and $5^{\prime} \mathrm{a}-\mathrm{H}$ have a trans configuration, and $11^{\prime}-\mathrm{H}$ and the $\mathrm{C}-10 \mathrm{~b}-\mathrm{C}-10 \mathrm{~b}^{\prime}$ bond have a trans configuration.

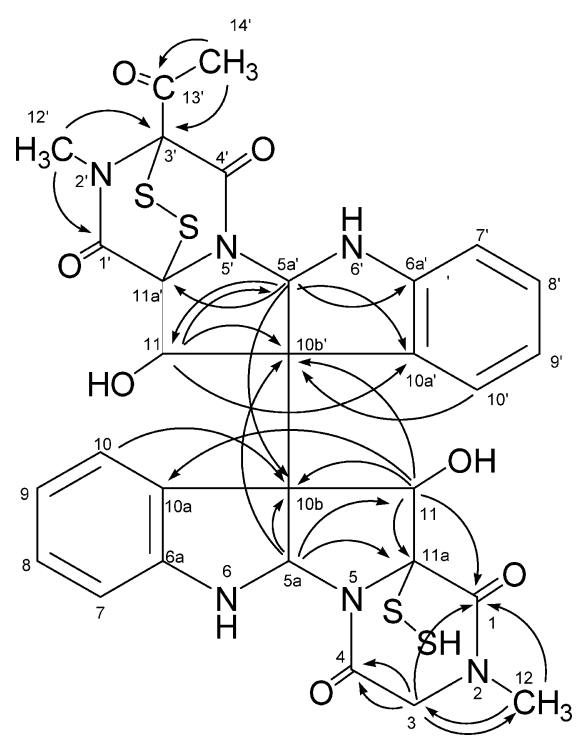

Fig. 2 Key HMBC correlations of $\mathbf{1}$.

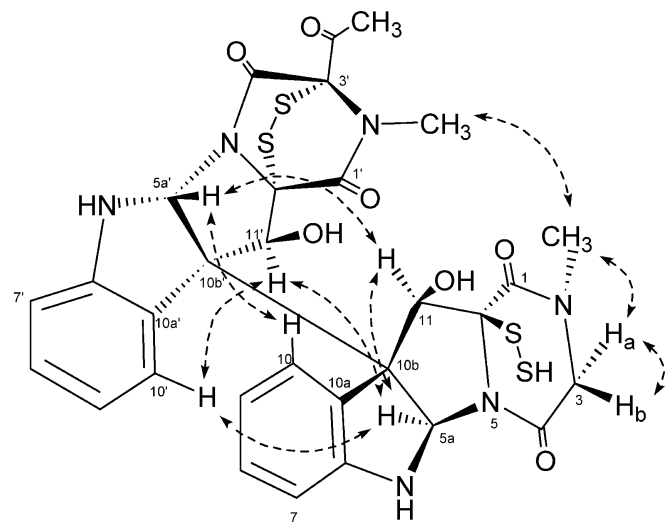

Fig. 3 Key NOE correlations of $\mathbf{1}$

However, 11-H showed NOEs with 5a-H and 5'a-H instead of $10-\mathrm{H}$. These data clearly indicated that $11-\mathrm{H}$ and $5 \mathrm{a}-\mathrm{H}$ have a cis configuration, and $11-\mathrm{H}$ and the $\mathrm{C}-10 \mathrm{~b}-\mathrm{C}-10 \mathrm{~b}^{\prime}$ bond have a cis configuration. Considering the absolute configuration of the congener 2 with the $[\alpha]$ value $\left(+225^{\circ}\right.$, $c 0.1, \mathrm{MeOH})$ virtually identical with that $\left(+220^{\circ}, c 0.1\right.$, $\mathrm{MeOH})$ of the literature [3], this data suggested the absolute configuration of $\mathbf{1}$ to be the same as that of $\mathbf{2}$ except for C-11.

1 and 2, the dimeric epidithiodioxopiperazines, exhibited antibacterial activity against $S$. aureus ( $S$. aureus RN4220 and $S$. aureus 503), MRSA (S. aureus CCARM 3167 and $S$. aureus CCARM 3506) and QRSA (S. aureus CCARM 3505 and $S$. aureus CCARM 3519). 1 showed stronger activity on QRSA with MIC $(\mu \mathrm{g} / \mathrm{ml})$ of 3 than against wild strains and MRSA with MIC $(\mu \mathrm{g} / \mathrm{ml})$ of 10 . Interestingly, 2 
showed stronger activity on wild strains and MRSA with MIC $(\mu \mathrm{g} / \mathrm{ml})$ of 3 rather than QRSA with MIC $(\mu \mathrm{g} / \mathrm{ml})$ of 10. The epidithiodioxopiperazine compounds such as verticillins, leptosins and Sch52900 were known to have antibacterial and antitumor activity [3,5]. The antitumor activity of Sch52900 was known to be due to the inhibition of $c$-fos proto-oncogene induction [7]. The active moiety of the epidithiodioxopiperazines with strong anti-MRSA activity, however, have not been reported. Thus, it is important to further investigate the structure-activity relationship of the epidithiodioxopiperazines.

Acknowledgment This work was supported by the 21C Frontier Microbial Genomics and Application Center Program, Ministry of Science and Technology (Grant MG05-0308-3-0), Republic of Korea. We express our thanks to Korea Basic Science Institute for NMR measurements.

\section{References}

1. Levy SB, Marshall B. Antibacterial resistance worldwide: causes, challenges and responses. Nat Med 10: S122-S129 (2004)

2. Pfeltz RF, Wilkinson BJ. The escalating challenge of vancomycin resistance in Staphylococcus aureus. Curr Drug Targets-Infect Disord 4: 273-294 (2004)

3. Joshi BK, Gloer JB, Wicklow DT. New verticillin and glisoprenin analogues from Gliocladium catenulatum, a mycoparasite of Aspergillus flavus sclerotia. J Nat Prod 62: 730-733 (1999)

4. Minato H, Matsumoto M, Katayama TJ. Studies on the metabolites of Verticillium sp. structures of verticillins A, B, and C. Chem Soc Perkin I 1819-1825 (1973)

5. Takahashi C, Numata A, Ito Y, Matsumura E, Araki H, Iwaki H, Kushida KJ. Leptosins, antitumor metabolites of a fungus isolated from a marine alga. Chem Soc Perkin Trans 1 1859-1864 (1994)

6. Takahashi C, Mioura K, Yamata T, Numata A, Kushida K, Shingu T, Hagishita S, Nakai H, Sato T, Harada H. Potent cytotoxic metabolites from a Leptosphaeria species. Structure determination and conformational analysis. Tetrahedron 51: 3483-3498 (1995)

7. Chu M, Ttuumees I, Rothofsky ML, Patel MG, Gentle F, Das PR, Puar MS. Inhibition of C-fos proto-oncogene induction by Sch 52900 and Sch 52901, novel diketopiperazines produced by Gliocladium sp. J Antibiot 48: 1440-1447 (1995)

8. Saito T, Suzuki Y, Koyama K, Natori S, Iitaka Y, Kinoshita T. Chetracin A and chaetocins B and C, three new epipolythiodioxopiperazines from Chaetomium spp. Chem Pharm Bull 36: 1942-1956 (1988) 